\title{
Analysis of the Function of English Language and Literature on Students' Language Ability
}

\author{
Li Zhu
}

Zaozhuang University, Zaozhuang, Shandong, 277160, China

Keywords: English language and literature, Students' language ability, Function.

\begin{abstract}
With the development of our country, English language learning has received a lot of attention and importance. However, English language and literature plays an important role in students' language ability. It is good for students to master their English language knowledge and enhance their learning effect. The process of its development gets good achievements. Therefore, teachers should make reasonable use of English language and literature teaching mode to carry out relevant work, and give full play to its role in the students' language ability.
\end{abstract}

\section{Introduction}

In English teaching, teachers need to focus on the cultivation of students' language ability, combined with English language and literature, develop a sound teaching program to guide students to fully understand the English cultural background and ideas, to some extent, to enhance students' knowledge of English knowledge and application ability to meet the current actual development needs.

\section{Analysis of the Present Situation of English Language and Literature Teaching Modes}

At present, the process of English language and literature teaching in our country, the teaching mode can be divided into three stages. The first stage is the teaching mode of knowledge transmission. During this period, teachers occupy the class as the main body of classroom teaching. Students can only learn knowledge passively. There is no good communication channel between teachers and students, and no equal relationship between teachers and students. It is difficult to cultivate students' ability of independent thinking, resulting in serious impact on students' learning and development. Student are lack of certain linguistic and applied abilities under the influence of transmission teaching mode. The second stage is the language structure type of teaching model; when the teachers are in the process of explaining cultural knowledge, literary texts and works are not connected with each other; they only use teaching works for students to explain knowledge; the classroom has the characteristics of one-sidedness, cannot guarantee students to develop good habits in the process of learning, and it is difficult to establish a complete teaching framework, which resulting in lower teaching efficiency. The third stage is the teaching mode of knowledge output of the peripheral environment. In the classroom teaching, the teachers will work directory and teaching chapters linked together for students to fully introduce and explain the teaching content, however, they cannot better interpret literary knowledge point, it is difficult to cultivate students' knowledge and practical ability, resulting in lower teaching efficiency. At the same time, teachers use such teaching mode, which with less educational space, lack of subjectivity of classroom teaching, unable to better analyze and understand English knowledge, leading to serious constraints on teaching work, or even lose the teaching goal, failed to reflect the advanced nature and reliability of various current teaching modes and make it difficult to carry out all aspects of management and control activities reasonably.

\section{Importance of Students' English Language Ability}

In the actual development of our country, the students' language ability is more important, and the 
society places more emphasis on the ability of language expression of the talented people, requiring them to have the basic skills, to form a good relationship in the process of interaction and to create a modern English language atmosphere. Therefore, in education and teaching, students' English language ability is more important. Teachers should pay enough attention to them and deal with them in a reasonable way. First of all, after having the language ability, students can better participate in interpersonal communication, handle complicated interpersonal relationships and enhance their employability in a highly competitive market. According to relevant surveys, we can see that most of our students have poor language skills. They cannot even express their true emotions in appropriate languages during interpersonal exchanges, and seriously affect their long-term development when their language skills are low. At present, most students come from one-child families, and they have selfish psychology, and they are lack of practical exchange and with low language skills. Second, most of the students lack the ability to apply language in the process of communication and cannot develop good habits in the process of communication. As a result, students cannot integrate into the man-machine relationship after entering the society and cannot enhance their overall accomplishment. However, after cultivating students 'language ability, teachers can use scientific teaching methods to enhance students' abilities and create a good atmosphere so that students can better integrate themselves into the social environment and strengthen their knowledge of English in the process of overall study ability to meet the current actual development needs.

This shows that in the process of student development. The cultivation of language ability is more important. Teachers should pay enough attention to it, use reasonable ways to train it, ensure that all aspects of work comply with the relevant provisions, gradually raise the level of education and teaching work, and coordinate the relations among all aspects of work so as to ensure the follow-up development and progress are laid the foundation.

\section{Analysis of the Components of Language Ability}

For students' development, language ability is more important. Basic knowledge and communication skills can be regarded as the main components to create a diversified management mechanism so that students can get good education and training in the actual development. Specific components for the following points:

\subsection{Essential Factor Analysis}

In the language application ability, the basic knowledge of language belongs to the most basic part, only the relevant knowledge, students can enhance their language communication and communication skills, to ensure that language skills are well developed. If students cannot fully grasp the basic knowledge of relevant language, it will lead to language norms and communicative competence are affected to some extent, it is difficult to achieve good communication and exchange, and even language communication problems, seriously affecting its long-term development.

The basic knowledge of the language, including: knowledge of the lexical is to learn how to use the vocabulary in the process of application of better expression of vocabulary in order to form a good learning mechanism. At the same time, it also includes the use of grammar, the method of composing clear words and sentences, grasps the grammar, and improves the students' language ability according to the language expression.

\subsection{Analysis of Elements of Communication Skills}

After mastering basic language knowledge, students also need to ensure that their language communication skills meet the relevant requirements. During their daily communication, they can communicate better through communication skills to enhance their language skills and ensure that under different language environments Reasonable use of relevant communication skills, and gradually improve their language skills. For language communication, it has certain complexity characteristics. Each sentence can express different meanings when speaking on different occasions. If it cannot be expressed in a reasonable way, it will affect the communicative competence. Therefore, in order to enhance the effect of language use, students should acquire relevant communicative skills, 
be able to express the language tactfully or directly on different occasions and environments, ensure a better understanding of relevant theories and get good achievements in language communication , Improve their communication skills.

\subsection{The Use of Language Rhetoric}

In the process of communication between Chinese and English, it is necessary to use reasonable rhetoric of language to express it. To a certain extent, it can enhance the effect of language use and better participate in communication activities. In order to ensure the effectiveness of language communication, the correct use of rhetorical art must be used. To a certain extent, it can achieve good purposes of use, enhance the accuracy of expression and enhance its appeal. Therefore, in the teaching of education, teachers should instruct the students to master the rhetorical and artistic forms of language to ensure that the language recipients can understand and analyze more easily and reach the purpose of emotional infect.

\subsection{Pay Attention to the Taboo of Life in the Cultural Background}

Language is the main tool of expression and expression of emotion. However, in the process of actual use, it is influenced by the context and cultural background, and some use problems may arise. During this period, language can be treated as cultural information under different cultural backgrounds by means of different communication and expressions to ensure the effectiveness of language application. During this period, students should understand the cultural background of English language. For example, most British people are more taboo in their beliefs and should avoid direct use of "AreyouCatholic?", "What'syourreligion", etc. during the actual exchange. Vocabulary about beliefs such as Catholicism should be avoided to affecting the effect of language exchange and communication. Therefore, teachers in actual teaching, need to guide students to fully understand the British cultural background in order to learn English knowledge, enhance and experience the ability [1].

\section{The Function of English Language and Literature on Students' Language Ability}

For language and literature, it is the highest level of language application. For English language and literature, during practical application, teachers can search for rich resources as the basis for students' learning and gradually improve their language ability. In English teaching, English language and literature can provide students with basic language knowledge, master the relevant communication skills, analyze the cultural differences between China and the West, and fully understand the cultural taboo in order to facilitate the application of English language, establish the correct concept, develop good habits and improve their language skills. The specific role of the performance of the following points:

\subsection{English Language and Literature as an Example}

Students in the process of learning English language and literature can be used as an example to better understand and master examples, to imitate the way of language expression, to improve students' language ability has a higher role. During the period of using English language and literature, students can make use of the examples of basic knowledge to better master the language application skills and reasonably choose the words to express in the language environment so that their English language application ability can be improved. At the same time, there are still more rhetorical skills in English language and literature. After learning, students can better master the relevant rhetorical skills, enhance their learning ability and ensure the learning effect in all aspects. And in the content of English language and literature, there are many differences in the application of language in different contexts. Students can apply English sentences reasonably according to relevant cultural contents, to a certain extent, to enhance teaching effectiveness and develop students' language ability.

\subsection{To Enhance the Mastery of Students’ Language Knowledge}

Students in English language literature work in learning activities, you can conduct a 
comprehensive analysis and masterpiece for each work, in understanding the basic knowledge of English language case, better application of relevant grammar to ensure that relevant language to master the use of skills. In the process of understanding and mastery of language knowledge, it is necessary to create a good space for development based on the contents of English language and literature, and to better experience the teaching environment and atmosphere according to the relevant context so as to gradually improve the learning effect. During this period, students can also expand the application of language knowledge, innovative teaching forms and student learning forms, to broaden the channels of knowledge of students to enhance their digestion and understanding of English knowledge to ensure the effectiveness of the application of language knowledge of students. At the same time, students are required to expand their own language knowledge and improve their language application ability and effectiveness while reading related English language literature and literary works. With the help of relevant skills, students can give full play to the positive role of literary knowledge [2].

\subsection{Improve Students' Language Skills}

Students in the process of learning English language and literature should have a certain degree of language skills, and be able to develop good habits of language application in practical development and create a good space for development. During this period, students can conduct a comprehensive analysis and mastery of English language literature and literature, enriching their own vocabulary, more accurate expression and description of the vocabulary. At the same time, students can learn different language expressions according to the different writing styles of different writers. During reading, students enrich their knowledge of language and enhance their language skills and abilities. In addition, in the teaching work, students can understand the English story better according to the relevant English language content, and to some extent, understand and analyze the characters' image, grasp the literary common sense content and ensure a better understanding and mastery new things. For students, in the process of improving their communicative competence, they need to subtly accept new things, enhance their language skills and English language knowledge, and ensure that they can develop good habits and achieve the expected teaching purpose in the future [3].

\subsection{Able to Fully Understand the English Language and Culture Background}

Students in the process of learning English knowledge through English language and literature, is conducive to a full understanding of the cultural background of the language, a better grasp of the relevant knowledge. Therefore, in the process of English teaching, teachers need to carry out teaching activities in a way that makes reasonable use of English language literature and literature, and deal with them through modern education and teaching methods to ensure the level of relevant work [4].

\section{Application of English Language and Literature in Improving Students' Language Ability}

In order to better cultivate students' language ability, English teachers should make rational use of English language literature and literature to carry out teaching activities and formulate sound educational programs and mechanisms to ensure that in the future development, a diversified management system will be established and all aspects of work content and requirements, the specific content and situation analysis. First of all, teachers should guide students to read related literary works, enhance their language sense, to ensure the quality of English teaching, with a lot of reading practice subtly to develop students' language ability, to ensure the quality of teaching. Second, it is necessary to clarify the specific teaching objectives and make efforts to cultivate students' understanding and mastery of English language literary works according to the current actual work requirements so that they can achieve good learning goals in the actual development process. At the same time, teachers also need to carry out language training activities, enabling students to fully understand and master the relevant knowledge and enhance the teaching of knowledge [5]. 


\section{Conclusion}

In the process of English teaching, if teachers want to cultivate students' language ability better, it is necessary to make reasonable use of English language literature and literature to carry out relevant work, to develop a sound teaching plan, to clarify the requirements and principles of various aspects of work, to coordinate various kinds of contents relationship, to ensure good habits are developed in the actual development of the process.

\section{References}

[1] Fan Mengyan. Corpus-based Comparison of Semantic Rhymes of Logical Result Language, Nanjing Normal University, 2015.

[2] Gao Yufei. The Role of English Language and Literature in Cultivating Students' Language Ability, Times Education, 2016 (9): 139.

[3] Zhou Ma. Study on the Current Situation of English Language and Culture Teaching in Primary and Middle Schools in Algeria, Anhui Normal University, 2014.

[4] Song Xiangyu. English Language and Literature on the Cultivation of Students' Language Ability, Shenzhou (middle), 2016 (5): 76-76.

[5] Zhang Wen. The Impact of Note-to-Speech on Alternative Translation, Shanghai International Studies University, 2014. 